ISSN: 0213-2087 e-ISSN: 2444-7080

DOI: https://doi.org/10.14201/shhcont372019191221

\title{
CINCO ARTÍCULOS DE NICETO ALCALÁ ZAMORA Y TORRES OLVIDADOS EN LA PRENSA FRANCESA
} (1936)

\author{
Five articles by Niceto Alcalá Zamora y Torres \\ forgotten in the french press (1936)
}

\author{
Miguel Ángel GARCÍA DE JUAN \\ IES Rosa Chacel (Madrid)
}

Recibido: 18/02/2019 Revisado: 18/07/2019 Aceptado: 02/09/2019

RESUMEN: El presente trabajo tiene por objeto la recuperación de cinco artículos de Niceto Alcalá Zamora que permanecían sin rescatar en el diario francés L'Intransigeant. Antes de trasladarlos aquí, traducidos, se ha considerado oportuno contextualizarlos mediante dos apartados. Uno referido a la figura pública del político andaluz, en el que se aporta información desconocida respecto a su acogida en el exilio francés en agosto de 1936. Otro, que trata de su modo de supervivencia en la nación gala con sus colaboraciones periodísticas en distintos países. Por lo que atañe al contenido de los artículos de don Niceto recuperados ahora, estos se centran, como otros que escribió entonces, en los defectos de los políticos que lo rodearon entre 1931 y 1936 y en las virtudes propias; cualidades siempre orientadas a buscar el equilibrio entre derechas radicales e izquierdas extremas y evitar un enfrentamiento armado. Tan elevado concepto de sí mismo evidencia, aunque en ocasiones le asista la razón, la gran autoestima de la que se acompañó siempre quien fue presidente de la Segunda República española.

Palabras clave: Alcalá Zamora; 1936; exilio; Francia; L'Intransigeant.

ABSTRACT: The purpose of this article is to recover eight articles by Niceto Alcalá Zamora that remained ignored in the French newspaper L'Intransigeant. Before transferring them here translated, it has been considered appropriate to contextualize them in two sections. One refers to the public figure of the Cordovan politician with provided unknown information regarding his reception in French exile in August 1936. The other one deals with his means of survival in the French nation with his journalistic collaborations in different 
countries. As far as the content of the articles by don Niceto now recovered is concerned, they focus, like many of his of the time, on the faults of the politicians who surrounded him between 1931 and 1936 and on his own virtues; qualities that are always aimed at balancing the republic and avoiding an armed confrontation. Such an elevated concept of himself is evidence, although he is sometimes assisted by reason, of the great self-esteem that was always attached to the former president of the Spanish Republic.

Key words: Alcalá Zamora; 1936; exile; France; L'Intransigeant.

\section{INTRODUCCIÓN}

En este año 2019 en que se rememora el septuagésimo aniversario del fallecimiento de Niceto Alcalá Zamora y Torres, la presente investigación tiene el propósito, como se indica en el resumen precedente, la aportación a unas posibles obras completas de cinco artículos ignorados hasta la fecha, los cuales fueron publicados en 1936 en el exilio francés. Procede aclarar que el breve apartado primero de este trabajo no pretende llevar a cabo un resumen de la biografía política de Alcalá Zamora ni mucho menos añadir nuevos hallazgos al respecto, pues su vida, ideas y actividad pública son harto conocidas. Es decir, trata de encuadrar los artículos que se recuperan dentro del itinerario político de esta destacada personalidad de la historia de España. Su existencia obedece, por tanto, en primer lugar, a una rápida presentación de los datos más significativos de su trayectoria pública previos al desempeño de las más altas magistraturas de la Segunda República española y, en segundo término, tras el anterior reducido pórtico de entrada, al recuerdo algo más detallado de su presidencia del Gobierno y, luego, del Estado, dado que es en este período de su vida (1931-1936) en el que se centra el contenido de las colaboraciones olvidadas en el diario parisiense L'Intransigeant.

\section{BREVE PERFIL PÚBliCO DE ALCALÁ ZAMORA, PERSONALIDAD POLÍTICA Y EXILIO EN FRANCIA}

Niceto Alcalá Zamora y Torres vino al mundo en Priego (Córdoba) el 6 de julio de 1877. Licenciado en derecho a los dieciocho años y letrado del Consejo de Estado a los veintidós, se afilió al Partido Liberal de Sagasta y luego al Partido Liberal Democrático de García Prieto, desde el que fue llamado a desempeñar los ministerios de Fomento y de Guerra durante el reinado de Alfonso XIII ${ }^{1}$. La aprobación por parte del monarca del golpe de Estado del general Primo de Rivera en 1923 lo orientó hacia el republicanismo, de tal modo que participó el domingo 17 de agosto de 1930, en San Sebastián, en la reunión y acuerdo de las principales figuras partidarias del derrocamiento de la

1. Diputado ininterrumpidamente entre 1906 y 1923. 
monarquía. Compareció allí como cabeza de su grupo Derecha Liberal Republicana, creada por él mismo tiempo antes.

Del Pacto de San Sebastián nació la decisión de derribar el régimen vigente, para lo cual se formó un comité revolucionario presidido por don Niceto y cuyos miembros tratarían de influir en el estamento militar, a fin de instaurar por la fuerza un nuevo sistema político. Como se comprobaría al constituirse el primer gobierno republicano, no por casualidad se había asignado a Alcalá Zamora, Sánchez Román y Lerroux la capitanía general de Burgos, pues se consideraba que en esa demarcación se encontraba «el núcleo principal de las fuerzas militares»².

Tras el desorganizado y fracasado alzamiento en armas de diciembre de 1930, fueron detenidos y juzgados varios miembros del aludido comité revolucionario, entre ellos, su presidente.

Instaurada ya la República, se llevaron a cabo elecciones generales el 28 de junio de 1931. En ellas, el partido de Alcalá Zamora obtuvo sólo 25 escaños, el que menos en comparación con los otros con que había concurrido ${ }^{3}$. No obstante, continuó ejerciendo la presidencia del Consejo de ministros que venía desempeñando desde el pasado abril.

En agosto de ese año cambió el nombre de su grupo político por el de Partido Republicano Progresista.

Al no ser atendidos sus criterios respecto a la presencia de la religión católica en la constitución que se estaba elaborando, renunció a la presidencia del Ejecutivo el 14 de octubre ${ }^{4}$. No obstante, el político cordobés aceptó ser nombrado presidente de la República, cargo que juró el 11 de diciembre, un día después de la publicación de la Carta Magna en la Gaceta de Madrid, aunque dicha ley de leyes hubiera terminado estableciendo la laicidad del Estado y de la enseñanza, así como la animosidad contra las órdenes y congregaciones religiosas.

Como presidente de la República convocó elecciones en 1933 y, presionado por republicanos y socialistas, de nuevo en enero de 1936. Aprovechando la ocasión don

2. ALCAlÁ ZAMORA, Niceto: Memorias. Barcelona: Planeta, 1998, p. 176.

3. A los aludidos comicios acudió en unión del PSOE, PRR, PRRS, ERC y AR.

4. Es difícil dudar de su inteligencia, información y cultura; con todo, cabe preguntarse si no prestó atención, no quiso percatarse o consideró indiferente que no pocos de sus compañeros del Pacto de San Sebastián del año anterior eran miembros de la masonería y, por tanto, no podían coincidir con sus creencias religiosas. GÓMEZ MOLLEDA, María Dolores, afirma a este respecto: «Tanto la opinión pública contemporánea como la historiografía posterior señalaron a la masonería como especial responsable de las leyes laicas de la República y de que las Constituyentes se vieran presionadas por su poderosa influencia. Representativo a este respecto resulta el texto de Alcalá Zamora [de 1945] en el que afirma que "la masonería" pesó mucho en el sectarismo de la Constitución y de las leyes; facilitó las disidencias y alianzas, cuando no las impulsó, precisamente para favorecer el sectarismo»: La Masonería en la crisis religiosa del siglo XX. Madrid: Taurus, 1986, p. 313. La misma autora recuerda en ese estudio que, de los 470 diputados de las Cortes Constituyentes, 151 eran masones. 
Niceto, como recuerda Stanley G. Payne, utilizó la porfía de esos grupos para que Manuel Portela Valladares, desde su posición privilegiada de presidente del Consejo de ministros, creara rápidamente el Partido de Centro Democrático a fin de presentarse a los comicios y, si no ganarlos, sí obtener un buen resultado. Pero su propósito acabó en un fracaso, pues tan sólo obtuvo 17 parlamentarios $^{5}$. En coincidencia con el historiador estadounidense, aunque desde un espacio ideológico diferente, afirma Santos Juliá:

Niceto Alcalá había actuado en los meses anteriores [a la convocatoria de 1936] como auténtico jefe de partido, dando el decreto de disolución a Portela Valladares y proponiendo su propio partido con el obvio resultado de un descalabro en las urnas. En buena lógica política, debió haber sacado la lección de esa aventura, que todos, por la derecha como por la izquierda, entendieron como una derrota personal, y haber dimitido de la presidencia de la República ${ }^{6}$.

Si como consecuencia de las elecciones de 1933 triunfaron las derechas, el resultado de las de tres años después fue el contrario. Con todo, republicanos y socialistas, o sea, los favorecidos por esta convocatoria, buscaron deshacerse de él acusándolo de haber transgredido el artículo 81 de la Constitución, el cual prohibía al jefe del Estado disolver una segunda vez el Parlamento, bajo su desempeño, sin motivo suficiente. He aquí lo establecido por tal precepto:

\section{$[\ldots]$}

El Presidente podrá disolver las Cortes hasta dos veces como máximo durante su mandato, cuando lo estime necesario, sujetándose a las siguientes condiciones:

a) Por decreto motivado

b) Acompañando al decreto de disolución la convocatoria de una nuevas elecciones para plazo máximo de sesenta días.

En el caso de la segunda disolución, el primer acto de las nuevas Cortes será examinar y resolver sobre la necesidad del decreto de disolución de las anteriores. El voto desfavorable de la mayoría absoluta de las Cortes llevará aneja la destitución del Presidente?

Constituido el nuevo Parlamento, en su primera sesión regular del 3 de abril de 1936, Indalecio Prieto, de acuerdo con Manuel Azaña, presentó una proposición que solicitaba a la Cámara que discutiera la decisión injustificada, según él, de haber disuelto

5. PAYNE, Stanley G.: El camino del 18 de julio. La erosión de la democracia en España (diciembre de 1935-julio de 1936. Barcelona: Espasa. 2018, pp. 63-67.

6. "El frente popular y la política de la República en Guerra». En: JULIÁ, Santos (Coord.): Historia de España de Menéndez Pidal, dirigida por José María Jover XL. República, Guerra Civil. Madrid: Espasa, 2005, pp. 114-115.

7. Gaceta de Madrid, núm. 344, 10 de diciembre de 1931, p. 1585. 
las Cortes en enero de ese año ${ }^{8}$. La iniciativa del diputado socialista9 la compartían no sólo Azaña y Casares Quiroga sino muchos más, tanto de izquierdas como de derechas. La votación para deponer al jefe del Estado se realizó el martes 7 de abril, en una maratoniana sesión que duró hasta las 0:35 del día siguiente. El resultado fue: 238 votos a favor de la destitución y 5 en contra, de un total de 417 diputados ${ }^{10}$.

Con esta medida parlamentaria Azaña y Prieto pretendían auparse, el primero a la jefatura del Estado y el segundo a la del Consejo de ministros. Aquél sí consiguió su propósito el día 11 de mayo, pero el diputado socialista no alcanzó el suyo por la oposición de su partido. Quien se situó al frente del Gobierno fue un estrecho amigo de Azaña cuando él se hizo cargo de la presidencia de República, Santiago Casares Quiroga ${ }^{11}$.

Alcalá Zamora en las jornadas previas al día 7 y aun ese día se resistió a presentar la dimisión que le solicitaban desde las Cortes, llegando incluso a intimidaciones y amenazas, puesto que consideraba que la disolución de 1933 no debía contar como primera, al haber tenido el carácter de Constituyentes, es decir, para él la primera disolución era la de 1936 y, por tanto, no procedía la aplicación el artículo 81 de la Carta Magna.

8. Como se ha dicho, las izquierdas venían solicitándolo hacía tiempo, con el fin de desplazar a la mayoría de derechas. Véanse $A B C, 8$ de abril de 1936, p. 15, y La Vanguardia de ese mismo día, p. 22. A este respecto afirma TUSELL, Javier: «Durante los dos últimos años, la izquierda había estado clamando por la disolución de las Cortes y, cuando el Presidente las disolvió, entonces le reprochó a Alcalá Zamora que había obrado incorrectamente». En: MARTÍN, José-Luis, MARTíNEZ SHAW, Carlos y TUSELL Javier, Historia de España 2. Edad Contemporánea. Madrid: Taurus, 2001, p. 338.

9. Prieto estaba pidiendo desde su periódico bilbaíno El Liberal la destitución de Alcalá Zamora ya un mes antes. Así puede comprobarse con la lectura del editorial «Las empresas que nos aguardan» del 30 de marzo de 1936, p.1.

10. La relación de votantes en uno u otro sentido la recogió, entre otros diarios, Ahora, 8 de abril de 1936, p. 6. Todo el proceso de separación de don Niceto de la presidencia de la República lo detalla con claridad PAYNE, Stanley G. en El camino al 18 de julio. La erosión de la democracia en España (diciembre de 1935-julio de 1936), ed. cit., 2018, pp. 137-146. Lo que dice Payne en este libro, editado por vez primera en 1916, coincide casi por completo con lo expuesto en otro, también de 2016: Niceto Alcalá Zamora, el fracaso de la República conservadora. Madrid: Gota a Gota-Faes, pp. 226-238.

11. Por tanto, la masonería se colocó en la dirección de las principales instituciones de la Nación: Diego Martínez Barrio al frente de esta, al sustituir interinamente a Alcalá Zamora, Luis Jiménez de Asúa en la presidencia interina de las Cortes, Manuel Azaña a la cabeza del Consejo de ministros. Cuando Azaña accedió a la jefatura del Estado, Martínez Barrio volvió a la presidencia del Parlamento, y del Gobierno se encargó Santiago Casares. Tarde reconoció don Niceto la influencia de esta sociedad secreta en la política española. A sus palabras de un texto de 1945 nos hemos referido con anterioridad, pero años atrás ya había tratado en sus Memorias a Martínez Barrio de manera mordaz, recriminándole sus malas artes protocolarias quizá aprendidas en "modestos talleres en el matadero o en la mondonguería" que visitaba. Y, al referirse a su ayudante de servicio el día 7, dice del comandante Jiménez Orge: "Yo observaba en él anomalías que le hicieron perder mi confianza y que me expliqué luego, cuando supe que era masón, pero verdaderamente intoxicado, pues, en rigor, vivía en la logia de la antigua calle del Príncipe». Memorias, ed. cit., p. 412. 
En su detallado repaso de lo sucedido en la política española entre diciembre de 1935 y julio de 1936, el ya mencionado historiador Stanley G. Payne señala:

De forma casi unánime los historiadores han condenado una destitución basada en palabras de su analista principal [Joaquín Tomás Villarroya] en «un argumento improcedente», y el acuerdo va desde el decano de la historia marxista del siglo XX en España, Manuel Tuñón de Lara, hasta Javier Tusell, el más notable especialista en la historia política de España en la última parte del siglo, pasando por otros muchos. Como ha dicho Villarroya «resultaba contraria a la Constitución y aun a la lógica fundamental»12.

A pesar de todo, Alcalá Zamora determinó asumir la destitución por las Cortes el reiterado 7 de abril de $1936^{13}$. El día siguiente de su separación de la jefatura del Estado el 7 abril de 1936, un periodista preguntó al conde de Romanones su opinión sobre lo ocurrido, a lo que contestó: "Yo recordaba anoche a última hora, dos fechas del mes de abril, la del 14 del año 31 y la del 7 del año 36. En aquella fecha, el propio Sr. Alcalá Zamora me decía que sólo le daba de plazo a la monarquía hasta la puesta del sol. A él no le habían dado ni si quiera ese plazo» ${ }^{14}$.

12. El camino al 18 de julio. La erosión de la democracia en España (diciembre de 1935-julio de 1936). Ed. cit., p. 144. Lo que dicen exactamente Villarroya (Catedrático de Derecho Constitucional) y Tusell es esto: "La destitución de Alcalá Zamora en los términos y modos en que se llevó a cabo resultaba contraria a la Constitución y aun a una lógica elemental»: La destitución de Alcalá Zamora. Valencia: Fundación Universitaria san Pablo CEU, 1988, p. 137; "El procedimiento utilizado para la destitución fue inadmisible por tortuoso e incongruente». En: MARTÍN, José-Luis, MARTÍNEZ SHAW, Carlos y TUSELL, Javier: Historia de España 2. La Edad Contemporánea. Ed. cit., pp. 337-338.

13. Amplia información acerca de la propuesta firmada en primer término por Indalecio Prieto y defendida por él en el Parlamento el 7 puede obtenerse de la lectura de los periódicos de los días 4 y 8 de abril. Interesa la consulta de tres medios, uno de derechas, otro de centro y un tercero, de izquierdas; o sea, del tradicionalista donostiarra La Constancia, del madrileño Abora y del prietista bilbaíno El Liberal, el cual dedica ocho páginas a lo acaecido el día 7. Además de las propias Memorias de Niceto Alcalá Zamora. Barcelona: Planeta, 1998 (comenzadas a redactar por segunda vez en 1940, después de haber sabido que las depositadas en España en Crédit Lyonnais las habían robado al comienzo de la Guerra civil y hoy felizmente recuperadas y publicadas con el título Asalto a la República. Enero-abril de 1936. Madrid: La Esfera de los libros, 2011), pueden leerse acerca de estas y otras cuestiones vinculadas con la figura pública del político cordobés, entre otros, los trabajos que se citan a continuación: JULIÁ, Santos: «El Frente Popular y la política de España en Guerra». En: JULIÁ, Santos (coord.) Historia de España de Menéndez Pidal dirigida por José María Jover XL. República y Guerra civil. Madrid: ed. cit. pp. 99-186; VILLARROYA, Joaquín Tomás: La destitución de Alcalá Zamora. Valencia: Fundación Universitaria San Pablo CEU, 1988; ALCALÁ GALVE, Ángel: Alcalá Zamora y la agonía de la República. Sevilla: Fundación José Manuel Lara, 2002; PEÑA GONZÁLEZ, José: Alcalá Zamora. Barcelona: Ariel, 2002; GIL PECHARROMÁN, Julio: Niceto Alcalá Zamora. Un liberal en la encrucijada. Madrid: Síntesis, 2005; PAYNE, Stanley G.: Alcalá Zamora. El fracaso de la Republica Conservadora, Madrid: Gota a gota-Faes, 2016; PAYNE G. Stanley: El camino al 18 de julio. La erosión de la democracia en España (diciembre de 1935-julio de 1936). Barcelona: Espasa, 2018.

14. ABC, 9 de abril de 1936, p. 32. El mismo día 9 La Veu de Catalunya publicaba en su página 18 resúmenes de los comentarios de ocho periódicos de casi todo el espectro ideológico español. 
No pocas fueron las solicitudes de periodistas para que el depuesto presidente de la República manifestara cuáles eran sus proyectos inmediatos, pero decidió no hacer ninguna declaración. Sólo indicó que, pasado un tiempo, expondría su parecer sobre lo que había sucedido. Transcurrido un mes, se facilitó desde su domicilio una nota de prensa que recogieron varios periódicos; uno de estos fue El Adelanto, de Salamanca. El comunicado informaba de la docena de políticos allí reunidos (llama la atención la usencia de Miguel Maura) y su propósito de trabajar, encabezados por don Niceto «en armonía con las otras fuerzas que asuman la tarea penosa de colocarse como esperanza de paz entre las contrapuestas de odio, agresión y dictaduras» ${ }^{15}$. Sin embargo, el proyecto no llegó a materializarse y el expresidente de la República comenzó a dedicar su tiempo a preparar el libro que se publicaría en junio Los defectos de la Constitución de 1931 y a escribir artículos para varios medios, en los que relataría y opinaría sobre lo acaecido en su desempeño de la jefatura del Estado, así como en su separación de este cargo el 7 de abril de 1936.

El día 6 de julio iniciaba, con su familia, un viaje por el norte de Europa del que no regresaría más a España. Pero de su exilio inmediato en Francia nos ocuparemos después.

Ahora, quizá sea oportuno recoger algunas opiniones acerca de la figura pública de Alcalá Zamora emitidas desde lugares opuestos del espectro político en los años en que fue una distinguida personalidad de la Segunda República española. Para no hacer largo este punto, se centrará únicamente en dos significativos momentos: el de su dimisión de la presidencia del Gobierno y el de su destitución de la jefatura del Estado. Tras su cese al frente del Consejo de Ministros el 14 de octubre de 1931, el diario republicano barcelonés El Diluvio decía en su cuarta página del día 16, a continuación de acusarlo de católico y de pertenecer al pasado: «Ni por su intelecto ni por su carácter es Alcalá Zamora para España el hombre de hoy. Débil, apocado irresoluto de regir los destinos del pueblo español, hubieran acabado por imponérsele los reaccionarios. El Nuncio hubiera sido, tras cortina, el verdadero amo de España». El libertario La Tierra del 17 conceptuaba a Alcalá Zamora como un Jano de la política: revolucionario hacia el exterior, pero conservador católico en su interior: «La cara que miraba al pueblo era distinta de la que ponía a Roma. Con Roma adquiría compromisos y al pueblo hacía concebir esperanzas. En público era fervoroso demócrata y en privado hipotecaba la propia personalidad al secular enemigo del pueblo: el Pasado» ${ }^{16}$. Por su parte, el tradicionalista El Siglo Futuro lo calificaba como "caudillo de la revolución» en su primera página del día 9 de noviembre y, un mes más tarde, el 4 de diciembre, en vísperas de aprobarse la Constitución, proclamaba: «Tenemos que hacernos a la idea de que estos son momentos de persecución, porque todos, sin distinción, incluso «los más católicos

15. El Adelanto, 7 de mayo de 1936, p. 7.

16. FERNÁNDEZ, Esaú, «Ya se fue. ¡Hosanna!», La Tierra, 17 de octubre de 1931, p. 4. 
que el que más», son, ante todo republicanos y aquí, en España no se concibe este régimen más que actuando en anticatólico, que es como se han producido desde los señores Alcalá Zamora y Maura, a pesar de sus palabras, hasta el demagogo del señor Albornoz".

Llegados los días inmediatamente posteriores a la deposición del político andaluz de la presidencia de la República el día 7 de abril de 1936, la generalidad de la prensa se manifestaba aún más crítica con él. En la jornada siguiente, el artículo sin firma del reiterado medio tradicionalista: «Don Niceto destituido. Saturno aplaca su hambre» recordaba que este había colaborado con la monarquía y que había sido ministro de Alfonso XIII. "Pero luego fue a Valencia para propugnar por el destronamiento del monarca y prometer a los españoles una República cuyo patrocinio ofrendaba a san Vicente Ferrer, evocando el Compromiso de Caspe». Añadía el articulista de El Siglo Futuro que quienes lo habían destituido de la presidencia le imputaban lo mismo que él había reprochado al Rey: «ejercer el poder personal y pretender imponer su voluntad en los asuntos políticos grandes y chicos ${ }^{17}$. Por su parte el republicano de izquierdas La Libertad editorializaba en su primera página del día 9 recriminando a Alcalá Zamora que «casi desde los primeros días de la implantación de la República [su intención hubiera sido] decididamente contrarrevolucionaria y antidemocrática». Además, se le hacía responsable de lo ocurrido en Asturias en octubre de 1934 y se aplaudía su destitución por el Parlamento. En el monárquico y católico $A B C$ del día10, Federico Santander titulaba significativamente su colaboración "La desastrada caída", en cuyo segundo párrafo afirmaba:

Al filo del quinquenio, en un día abrileño, igual a aquellos de 1931, el exministro del Rey que enriqueció nuestra oratoria con el más elocuente y fervoroso elogio de la Realeza y de la Corona es destituido con prisa y con violencia del cargo al que le alzó su veleidad. Y lo que da a la destitución su máximo carácter de castigo es que, en esta hora de desgracia, el caído no tiene ni un sola voz en su defensa. Ninguna se oyó en el Parlamento. Fuera de él, lo mismo en los salones que en las calles, los comentarios coinciden en estas exclamaciones espontáneas: «iMerecido lo tiene!» «iBien empleado le estál».

El periodista de $A B C$ estaba en lo cierto, como hemos adelantado más arriba, al afirmar que el comportamiento de don Niceto lo había conducido a la marginación de casi todos los políticos y a la crítica general, pues hasta el moderado El Sol del mismo día 10 le recriminaba en el editorial "Causas de la Caída» su autoritarismo y ambición, y añadía que, desde su posición de privilegio de presidente de la República, intentó desplazar a los partidos consolidados mediante la creación de un partido político propio, «entregando para ello todos los resortes del Poder a un grupo de amigos, [pero] el

17. P. 8. Del mismo modo, el también periódico carlista de San Sebastián La Constancia publicaba este artículo en la página primera del día 11. 
sufragio universal borró a los candidatos ministeriales de las urnas y barrió al Gobierno comanditario el clamor de la calle. El resultado electoral para los centristas fue la más rotunda desautorización. El país le volvía también las espaldas» ${ }^{18}$. Este mismo periódico recogía el día 11 unas palabras pronunciadas por Francisco Largo Caballero en un acto organizado por la Sociedad de Albañiles de la UGT:

El presidente fue desleal para las derechas, izquierdas y centro. Tiene una responsabilidad que no se puede olvidar: fue el responsable de lo de octubre. Sabía que, si la CEDA entraba en el Gobierno, estallaría la revolución [...]. Y ese presidente ha sido echado, no por acuerdo del Parlamento, sino por la revolución de octubre. Todo gira alrededor de la revolución y, a no ser por octubre, no le hubiera venido el 16 de febrero. [...] Ya visteis que el Sr. Alcalá Zamora siempre daba el poder a las derechas o a elementos incoloros a su servicio. Si no hubiera sido por el Sr. Alcalá Zamora, no hubiera habido 10 de octubre. Nos equivocamos cuando elegimos al Sr. Alcalá Zamora ${ }^{19}$

Cabe preguntarse si no existió alguna opinión comprensiva o elogiosa de la figura política del político cordobés. Para obtener una respuesta positiva, hay que acudir a alguno de sus más cercanos colaboradores y amigos. Este es el caso de Miguel Maura, quien dejó escrito: "Nuestro presidente era un hombre originalísimo y excepcional. En primer lugar, era bueno, de gran corazón y de una honradez y limpieza de conducta, en todos los órdenes de la vida, inimaginables» ${ }^{20}$.

18. El periódico anarquista barcelonés Solidaridad obrera del día 11, en su página 8, se mostraba el más inmisericorde de todos los que hemos leído. Recordaba el pasado monárquico de don Niceto. Le reprochaba su catolicismo. Le culpaba de los hechos de octubre de 1934, por entregar el Gobierno al Partido Republicano Radical y a la CEDA, pues «Las brutalidades cometidas por Lerroux-Gil Robles las compartió. Las torturas, los atropellos, el trato de cabileños no halló la repulsa del personaje que encarnaba el poder moderador». Además, «Pisoteó continuamente la Constitución. Fue propugnador de la reforma constitucional. Alentó en este sentido a las derechas. [...] Gozaba de fama de parlamentario. Sus discursos reflejaban un tono académico. Su pose era la de un engreído».

19. El Sol, 11 de abril de 1936, p. 5. Con una crudeza desmedida lo retrató Manuel Azaña en 1937. Después de presentarlo como un altilocuo al que le aparecía espuma en los labios cuando hablaba, irritable y con un defecto en una pierna, manifestaba: «La incapacidad de mentirse a sí mismo a sabiendas, reforzada por sus escrúpulos de conciencia muy ostentados, así como la de frenar o expulsar las ideas delirantes, debían de contribuir mucho a agravar sus torturas. La imaginación de Alcalá Zamora no era fértil, vivaz, caprichosa, sino árida, triste monótona, dentro de una complicación interna como las fojas de un pleito, y sus más demandadas invenciones concluían con un tormento personal, como nacidas de la persuasión de que todos se conjuraban para vetarlo y atormentarlo", Obras completas 6. Madrid: Centro de Estudios Políticos e Institucionales, 2007, p.434. Azaña ya había dado pruebas de su ensañamiento con el presidente de la República en muchas páginas de sus Memorias políticas (1931-1933). Barcelona: Mondadori, 1996. Léase como ejemplo la página 678

20. Así cayó Alfonso XIII... Barcelona: Ariel, 1995, p. 212. Miguel Maura, a pesar de la defensa de Alcalá Zamora que llevó a cabo el día de su destitución, le criticó no haber acelerado el proceso de la República: "Yo consideré y considero que el presidente de la República no imprimió a esta la marcha que 
A pesar de los esfuerzos, por lo general bien intencionados de Alcalá Zamora, las luchas y disputas políticas entre izquierdas y derechas, ambas intransigentes, presagiaban, no sólo para don Niceto, el paso de la guerra civil de las palabras, como señaló Unamuno $^{21}$, a la de las armas.

Aprovechando la libertad de que disfrutaba tras el abandono forzado de la presidencia de la República, comenzó el 6 de julio un viaje, con toda la familia, por distintos países del norte de Europa. El periódico santanderino El Cantábrico de ese día informaba en su primera página de su llegada el anterior a la capital de la Montaña y de que embarcarían en la siguiente jornada en la motonave Caribia. El primer destino fue Hamburgo; después Edimburgo, donde se enteraron de la rebelión militar en España; a continuación se dirigieron a Islandia, país en el que se informaron de la gravedad de lo que estaba sucediendo; finalmente, arribaron a Noruega, desde donde se encaminaron a Berlín, ciudad en que don Niceto realizó gestiones con el propósito de establecerse en París.

Varios periódicos franceses recogieron, con mayor o menor extensión, la llegada de Alcalá Zamora a la capital de la República y su deseo instalarse en ella. Si bien Le Petit Parisien (el diario de mayor tirada de Francia) del día 11 de agosto en tres párrafos de su primera página, con el título "Le séjour à Paris de M. Alcalá Zamora», daba noticia de ello, los rotativos que más espacio dedicaron a su arribo a la capital gala fueron L'Intransigeant, el cual le ofreció inmediatamente sus páginas para que colaborar en él, y Paris-Soir, cuyo suplemento dominical también estampó algún artículo suyo. Igualmente, colaboraría durante varios años, como se recordará luego, en el diario L'Ére Nouvelle.

L'Intransigeant del 11 de agosto dio cuenta de una larga entrevista de don Niceto con el periodista Jean Antoine en las páginas primera y tercera. La conversación había tenido lugar en el rápido de Berlín a París. El entrevistado declaraba que él expulsó al Rey sin derramar una gota de sangre, mientras ahora las derechas y las izquierdas se hallan completamente enfrentadas: «Les gauches attaquaient un professeur à l'Université, le plus grand orientaliste de ces temps, parce qu'il était prêtre. Des droits demandaient la tête d'un président de la Cour de Cassation parce qu'il n'était pas baptisé». Se declaraba católico practicante pero defensor de una República en que imperase la libertad de conciencia. Añadía que había adivinado que, tras las elecciones de febrero de ese

le convenía, y yo, por mi parte, he hecho cuanto he podido para que la República mantuviera su verdadero ritmo. Como persona, el señor Alcalá merece todos mis respetos, pero como jefe del Estado ha perdido todo su prestigio y yo, en consecuencia, hubiera votado la censura», El Sol, 8 de abril de 1936, p. 4. Y es que, a medida que discurrió el tiempo, surgieron los desacuerdos entre ambos. Para Maura, no obstante, la figura de don Niceto, "pese a sus errores, que los tuvo, sale nimbada de una aureola de bondad, de patriotismo, de rectitud, de honradez acrisolada y de ferviente deseo de acierto, virtudes congénitas en él que plasmaron su respetable personalidad", Ibídem, p. 216.

21. UNAMUNO, Miguel de, "El espolón y el codaste», Ahora, 14 de abril de 1936, p. 5. 
año, se iba a llegar a un enfrentamiento armado, como estaba ocurriendo. Él pretendió representar la conciliación, pero lo expulsaron de la presidencia. A la pregunta de qué pensaba hacer en el futuro, respondía que de América le habían ofrecido hospitalidad, pero él prefería Francia o Portugal. El mismo día 11 publicaba Paris-Soir, en su página tercera, otra entrevista, en este caso con Louis Fleury. Interrogado sobre lo que sucedía en España en esos momentos, respondía que no disponía de suficiente información, y, en cuanto a su pasado político inmediato, contestaba: «Tout le temps qu'a duré mon mandat je me suis efforcé d'apaiser les passions et de concilier les partis en présence. Mais vous connaissez, hélas! certaines propensions de l'esprit espagnol aux luttes fratricides..."22.

El 21 de noviembre el reiterado L'Intransigeant estampaba en su cuarta página dos entrevistas de Mery Bromberger, una con Pío Baroja y otra con expresidente del Estado español. Las titulaba «L'Espagne en exil à Paris». Circunscribiéndonos a lo manifestado por el político cordobés, afirmaba que él siempre había sido moderador: "protegeant les droits contre les excès des gauches au pouvoir et le gauches vaincues contre les représailles des droites». Elogiaba a las derechas e izquierdas francesas, porque no eran tan extremistas como las españolas, pues en España existe el virus de la guerra civil. Concluía afirmando que en Francia sólo disponía para vivir de lo que conseguía con sus artículos. Así lo ratificó en sus "memorias»: "Económicamente vivía en perpetua zozobra, no de apuro extremo e inmediato, pero sí de incertidumbre inquieta. Fuesen cuales fuesen los motivos de mi cese en L'Ėre Nouvelle, esa colaboración fue mi principal medio y es el recuerdo más grato, que se extiende en menor escala a algunos otros trabajos ocasionales en grandes periódicos de París y en algunas revistas ${ }^{23}$. Antes de centrarnos en sus textos periodísticos, más en concreto en los franceses desconocidos hasta hoy en España, parece oportuno detenerse en algunos episodios de cierto relieve en la vida del político cordobés durante su permanencia en el exilio en Francia: el asalto en Madrid al poco de comenzar la guerra al Banco Hispanoamericano, con el fin de apoderase de la alhajas de su mujer y de sus hijas; el paso de dos de sus hijos desde Francia a España, a finales de diciembre de 1936, con el objeto de unirse al ejército de la República ${ }^{24}$; otro asalto, ya en 1937, al Crédit Lyonnais, a fin de hacerse con lo

22. Otra conversación de menor interés entre Alcalá Zamora y Robert Guyon apareció también el día 11, en la página 11 de Le Journal.

23. Memorias, ed. cit., p. 491. La razón del cese de las colaboraciones en L'Ère Nouvelle estuvo, según Alcalá Zamora, en el acercamiento del periódico al embajador en París del nuevo régimen español Félix María de Lequerica, ibídem, p. 488. En estas Memorias, también se refiere a su asesoramiento a bancos franceses sobro sus intereses en entidades de la España en guerra, pp. 443-446.

24. El periódico L'Intrasigeant no otorgaba casi espacio al hecho, probablemente para no causar mayor dolor a su padre. Solo daba la noticia en unas líneas del número del día 28, p. 3, de que José y Luis habían llegado a Valencia, pasando por Barcelona, a luchar por la República. El que sí daba amplio espacio a la determinación de los dos hijos de Alcalá Zamora era el comunista L'Humanité del día 27, y lo hacía con 
guardado allí, incluidas sus "memorias», las cuales hubo de reescribir en el exilio; la muerte por una enfermedad hepática de su hijo José en un hospital de Valencia el 21 de marzo de 1938; el fallecimiento de su esposa en Pau el 13 de mayo también de ese año, adonde se había trasladado la familia desde París el día 5 de aquel mes.

Dos años más duraría su estancia en territorio francés, pues don Niceto decidió trasladarse a Argentina ${ }^{25}$. Con este fin, llegó a Marsella el 15 de noviembre de 1940 para embarcar en el vapor francés Alsina, pero la salida se retrasó dos meses, hasta finales de enero de 1941. Además, el accidentado viaje a Buenos Aires se prolongó hasta el 28 de marzo de 1942, es decir, duró más de un año, el cual recordó en un libro titulado 441 dias. Un viaje azaroso de Francia a la Argentina.

Fallecería en Buenos Aires el 18 de febrero de 1949.

\section{PRESENTACión de las COlaboraciones OlVIDADAS EN L'INTRANSIGEANT}

Ha quedado dicho en el apartado anterior que el exjefe del Estado español subsistió en Francia gracias fundamentalmente a sus colaboraciones en la prensa francesa, argentina... En la capital de este país suramericano publicaron artículos suyos Leoplan, Chabela, Aquí Está, La Prensa y La Nación ${ }^{26}$ y en Francia L'Intransigeant, Paris-Soir y L'Ére Nouvelle. Todos los escritos en la lengua de Molière debieron de ser traducidos a ella desde el español, puesto que don Niceto carecía de competencia idiomática francesa, al menos en lo que se refiere a la expresión hablada ${ }^{27}$.

Los artículos de Argentina, a excepción de los de La Prensa, que están a punto de recuperarse en Obra completa ya han sido publicados en volúmenes anteriores.

gran regocijo, alabando a José «communiste» ya Luis «socialiste», a la vez que atacaba cruelmente a su padre, quien, con sus decisiones había originado «le coup fasciste en Espagne».

25. Algunos de quienes se han ocupado de su exilio en Francia han sido, además del citado Gil Pecharromán, ROBLES MUÑOZ, Cristóbal: "Alcalá Zamora: un republicano demócrata cristiano", Hispania Sacra, LXIV, extra I, enero-junio, 2012, pp. 69-148; RUIZ-MANJÓN CABEZA, Octavio. En: MARTÍNEZ, Fernando, CANAL, Jordi y LEMUS, Encarnación (eds.): "Alcalá Zamora y Azaña, dos expresidentes de la República española en el exilio francés", (eds.): París ciudad de acogida. El exilio español durante los siglos XIX y XX. Madrid: Marcial Pons, 2010, pp. 235-248; DURÁN ALCALÁ, Francisco: «El exilio de Niceto Alcalá Zamora», Andalucía en la Historia, enero 2014, n 4, pp. 36-39.

26. En La Nación había empezado a escribir antes de la salida de España en julio de 1936; así lo ratifica su Obra completa. Artículos publicados en La Nación (Buenos Aires, 1936-1939): Parlamento de Andalucía-Diputación de Córdoba-Cajasur-Patronato "Niceto Alcalá Zamora y Torres», 2003. El primer artículo en este prestigioso periódico bonaerense lleva fecha del 23 de junio de 1936 y se titulaba: «Inventario objetivo de cinco años de República (1)».

27. Esto era lo que declaraba a Jean Antoine en la citada entrevista publicada por L'Intransigeant el 11 de agosto de 1936, p. 3: «Excusez-moi, je parle mal le Français, J'ai une excuse; je suis andalou; nous avons déjà tellement de difficultés à prononcer correctement l'espagnol...” 
Igualmente se han rescatado en ella los de L'Ére Nouvelle ${ }^{28}$. En consecuencia, faltan de conocerse en España las colaboraciones en L'Intransigeant y Paris-Soir. Aunque no hemos podido llegar a estas últimas, hemos localizado las del primer diario citado: cinco de la segunda mitad de 1936. Las ofrecemos aquí traducidas, siguiendo el procedimiento con el que los de L'Ére Nouvelle se han publicado en el correspondiente volumen de Obra completa ${ }^{29}$.

De los artículos de este diario y de los de La Nación, que suman más de un centenar, se ocupa Julio Gil Pecharromán en varias páginas del ya nombrado libro Niceto Alcalá Zamora. Un liberal en la encrucijada.Traemos aquí su examen de los contenidos de dichos escritos periodísticos del político prieguense, porque en muy considerable medida coinciden con lo que el autor manifiesta en los que recuperamos aquí:

[En La Nación y L’ère Nouvelle] expone su visión sobre el rumbo que ha seguido la República y el papel que él ha jugado en ella. [...] No hay trazas de objetividad autocritica [...], sino un análisis de las torpezas y egoísmos de la clase política, de los procesos de radicalización social experimentados y de las oportunidades perdidas por el régimen. Oportunidades que residían, básicamente, en una meritoria tercera España de la que él se consideraba representante ${ }^{30}$.

Los artículos que escribió Alcalá Zamora para el periódico centrista L'Intransigeant (1880-1948) aparecieron los días 15, 17, 18 y 27 de agosto y el 1 de diciembre de 1936. En este rotativo había tenido amplio eco la destitución del presidente de la República española, el cual se extendía con largueza en una crónica del 9 de abril de 1936

28. En un correo electrónico del 5 de diciembre de 2018, en el que el autor de este trabajo preguntaba a don Francisco Durán Alcalá, presidente del Patronato "Niceto Alcalá Zamora» de Priego (Córdoba), si se habían publicado en dicha Obra completa sus colaboraciones en francés, me contestó muy amablemente y con rapidez, informándome, entre otros detalles, de que solo habían rescatado las de L'Ère Nouvelle, si bien seguirían recuperándose en ella más escritos del expresidente de la República española.

29. La traducción ha sido una labor personal, la cual ha contado con la contribución de Philippe Marin Muracciole, por la que le quedo muy agradecido. De todas formas, se mantienen los títulos en francés, dada su fácil traducción al español. Acaso no sobre indicar que la traslación al español de los artículos de L'Intransigeant ha resultado, en ocasiones, fatigosa porque, como dice Diego Martínez Barrio en sus Memorias, muchos de los escritos de Alcalá Zamora adolecían de "rebuscamiento y culteranismo", y de períodos oracionales muy largos, añadimos nosotros.

30. Y agrega, pero ya refiriéndose a escritos en esos dos periódicos posteriores a los que se recuperan en este trabajo: «Frente a la disección minuciosa del pasado reciente, los artículos de Alcalá Zamora durante la guerra civil no abundan en comentarios sobre el desarrollo de la contienda o los políticos de ambos bandos, quizás por el hecho de que siendo un refugiado en un país neutral debía mantener ciertas cautelas al respecto. Hay, sin embargo, rotundas condenas a las represalias y asesinatos en la retaguardia, reflexiones sobre el equilibrio cambiante de las fuerzas en la España republicana y juicios sobre el carácter fascista del régimen de Franco y la imposibilidad de una restauración monárquica a corto plazo. Su visión sobre el futuro de España, cargada de pesimismo, era tan lúcida que ya en enero de 1938 escribía en La Nación lo que iba a ser el abismo entre vencedores y vencidos en la "posguerra franquista». Madrid: Síntesis, 2005, pp. 379-380. 
firmada por Jean Antoine el día anterior. He aquí el titular: «En quelques heures dans un calme apparent, le président Zamora a été destitué». El corresponsal del periódico galo, después de relatar lo ocurrido en las Cortes y la actuación de estas en relación con el jefe del Estado, pedía a los franceses que observaran la situación política española con imparcialidad.

Antes de pasar nosotros a destacar algunas partes de los contenidos de los artículos que se rescatan aquí, parece oportuno ofrecer una información desconocida más, relacionada con los tres primeros de L'Intransigeant. Gaceta de Tenerife de los días 17, 18 y 19 de junio de 1936 había llevado a sus primeras páginas, dividido en tres entregas, un artículo de Alcalá Zamora en el luso Diário de noticias del 1 de ese mes. "Cómo fui y dejé de ser presidente de la República Española» rezaba el encabezamiento en el rotativo canario. Este escrito periodístico del político prieguense presentaba un gran parecido con los tres primeros que publicaría a mediados de agosto el aludido diario francés. O sea, L'Intransigeant, repetía, ampliándolo y con variantes, lo que se había podido leer en el periódico lisboeta y en el tinerfeño. Con todo, conviene realizar las siguientes precisiones. L'Intransigeant añadía al comienzo de los artículos de los días 17 y 18 de agosto una considerable ampliación; en cambio, en Gaceta de Tenerife había ciertas líneas en el interior del texto que faltarían en el periódico francés. (El caso más significativo, el de un largo párrafo del final de la primera entrega en el que expone una de las ideas que repite continuamente en sus artículos: el desempeño de su cargo de presidente con imparcialidad, con la firmeza, además, de «acortar (sic) el paso a quien pudiese amenazar a la República en cualquiera de las dos significaciones [derechas e izquierdas]»). Alteraciones de menor relieve se hallan en la redacción de algunos fragmentos y en los encabezamientos largos de los apartados intratextuales en Gaceta de Tenerife en comparación con los más breves del diario parisiense ${ }^{31}$.

Tres son los principales núcleos en torno a los que giran los artículos que se recuperan aquí: Reproches a varios partidos políticos, a políticos concretos y a las Cortes. Frente a ellos aduce sus propios méritos. Todo esto referido al período que abarca desde el 7 de enero de 1936 en que disolvió el Parlamento hasta su destitución el 7 de abril. En menor medida también manifiesta sus impresiones y deseos de que termine la Guerra Civil, así como el mejor futuro para España.

31. Las páginas del periódico canario (1910-1938) se dividen en seis columnas. El escrito de Alcalá Zamora ocupaba tres de ellas. Las otras tres las llenaba el artículo de Rafael Salazar Alonso «Juicios de un exministro", el cual se extendió hasta el día 20, en que ocupaba por completo la página primera. Salazar Alonso vertía una serie de reproches a don Niceto, bajo cuya presidencia había desempeñado el cargo de ministro de la Gobernación (del 1 de marzo al 9 de septiembre de 1934), mientras eran jefes del Ejecutivo Samper y Lerroux. Si duras eran las críticas del aludido ministro, miembro de la masonería, como los dos últimos citados, mayor fue la contundencia con la que respondió el católico Alcalá Zamora en las páginas 323-324 y 596-598 de sus Memorias, ed. cit. 
En el Parlamento preponderaban las extremas derechas e izquierdas. Allí se llegaba a hechos tan absurdos como querer expulsar a eminentes científicos por su condición de sacerdotes y a hacer lo mismo con el presidente del Tribunal Supremo porque no estaba bautizado (In. II $)^{32}$. Los partidos de izquierda lo presionaron para que convocara elecciones desde bastante tiempo antes del 7 de enero y, luego, promovieron su destitución, incluso habiéndose beneficiado en los comicios de febrero (In. I) ${ }^{33}$. La izquierda republicana pretendió con su deposición «volver al poder y no perderlo nunca» (In. III).

El blanco de sus más acerados dardos lo fijó en el presidente de las Cortes, Diego Martínez Barrio, y en el del Gobierno, Manuel Azaña. Al primero lo acusó de taimado, que ocultaba su doblez sirviéndose de un exagerado protocolo, pues la jornada anterior a su destitución le propuso arteramente que renunciara a la jefatura del Estado, sin avisarle de que en caso contrario sería depuesto el día siguiente, 7 de abril de 1936 (In. III $)^{34}$. Del segundo, implícito en el apartado «La izquierda republicana» del artículo III, decía que la acción de Martínez Barrio había sido acordada con él.

A su juicio, la separación de su presidencia de la República que llevaron a cabo las Cortes fue por completo ilegal; es más, se trató de un "golpe de Estado» (In. III) ${ }^{35}$. Ya el primero había sido la decisión del Parlamento de declararse indisoluble, bajo la sospecha o el temor de que pudiera convocar nuevas elecciones. Entre los días 3

32. Se citará L'Intransigeant con la abreviatura In.

33. ALCALÁ GALVE, Ángel, en su benévola biografía de don Niceto declara que este no debía haber disuelto el Parlamento, pero no porque tal decisión se opusiera al Art. 81 de la Constitución. Para él «disolver las Cortes en tales circunstancias políticas sumamente volátiles, aunque medida plenamente constitucional por no hacer en el cómputo del Art. 81, no era necesaria [...]. Alcalá Zamora debió apurar las posibilidades parlamentarias venciendo su profunda repugnancia a dar el Gobierno a Gil Robles, secundado, si no por los radicales de Lerroux, ya tan impotentes, por los pequeños grupos de centro. Lo que España necesitaba era precisamente un Gobierno fuerte con la necesaria base democrática y las Cortes votadas en noviembre de 1933 se lo ofrecían con suficiencian: Alcalá Zamora y la agonía de la República. Sevilla: Fundación José Manuel Lara, 2002, p. 677.

34. Martínez Barrio trata de Alcalá Zamora en sus Memorias de forma más mesurada que este a don Diego. El presidente del Parlamento en aquellos días no ahorró palabras en señalar que el político cordobés y Azaña se desdeñaban, si no se odiaban. Respecto al asunto de la deposición del Jefe del Estado por las Cortes, consideraba, como sostenía don Niceto, que la disolución de 1933 no debía contar a efectos del Art. 81 de la Constitución, al haberse tratado de Constituyentes. Además, frente a lo que afirmó Alcalá Zamora en sus Memorias, indica que él actuó con total buena fe cuando lo visitó para recomendarle que dimitiera y así ahorrarle el mal trance de la proyectada destitución, MARTíNEZ BARRIO, Diego: Memorias. La Segunda República Española vista por uno de sus principales protagonistas. Barcelona: Planeta, 1983, pp. 310-318.

35. En su diario robado durante la Guerra Civil y recuperado no hace mucho tiempo, había escrito el 8 de abril de 1936, en medio de una serie de quejas y lamentos, que a las 11 de la mañana le visitó un coronel de Estado Mayor para pedirle que «en respuesta al golpe de Estado de la Cámara, yo, sin poder legislativo, firme un decreto destituyendo al Gobierno de Azaña", pero se negó a suscribirlo, ALCALÁ ZAMORA, Niceto: Asalto a la República. Enero-abril de 1936. Madrid: La Esfera de los libros, 2011, pp. 409-410. 
y 7 de abril de 1936, las Cortes lo tuvieron incomunicado con el Gobierno, aislado y manipulando la prensa (In. III).

En contraste con las críticas a órganos políticos y personas concretas, Alcalá Zamora se muestra desde el principio como la persona elegida para presidir el Gobierno y, luego, la República, por sus muchos méritos (In. I). Uno de los principales, el haber logrado la transición pacífica de la monarquía al régimen republicano (In. I). Otra de sus virtudes, cuya reiteración induce a sospechar conciencia de lo contrario, consistió en su comportamiento imparcial en la composición de los gobiernos (In. I). Si alguna vez se inclinó hacia un lado, lo hizo en beneficio de las izquierdas: "Mais si je quelquefois transgressé cette règle d'impartialité, je suis obligé de constater que je l'ai fait uniquement en faveur des Parlements de gauche qui m'ont renversé» (In. I). Se considera un «hombre de buena fe» (In. I), moderador y mediador entre los extremos, actitud que desagradó a las izquierdas, las cuales respondieron proponiendo y consiguiendo sus destitución, mediante la utilización ilegítima del artículo 81 de la Constitución (In. II). En varias ocasiones reitera que la disolución del Parlamento en enero de 1936 no fue la segunda bajo su presidencia sino la primera, pues la de 1933 era obligada, al tratarse de Cortes constituyentes, pero la mayoría de los partidos no lo consideró así y lo depusieron de la jefatura del Estado. Él pensó en resistir, en recurrir e la legislación que amparaba sus derechos, pero la situación estaba tan complicada que decidió someterse a la decisión del Poder legislativo. De no haberlo hecho, podían calificarlo después de ambicioso y causante de una guerra civil. Así termina el artículo de 18 de agosto de L'Intransigeant: "On aurait pu croire que l'ambition me guidai, tandis que j'accomplissais seulement mon devoir. Parmi les complexités de ce devoir, j'ai cru, je crois et je croirai toujours que ce qui était fondamental, c'était de ne contribuer à ce que s'avivât, s'aggravât, s'étendit la lutte déchainée par les passions des autres». Este apartamiento significó para él la libertad y la tranquilidad, pero España derivaría hacia un enfrentamiento fratricida.

Con el fin de que el que se había desencadenado concluyera lo más pronto posible, proponía un acuerdo entre naciones. Pero lo principal debía ser que, silenciadas las armas, resurgiera el "espíritu nacional», el que habiendo escrito la página sin igual, prodigiosa, del 14 de abril, trascendental y pacífica, no tiene derecho a destruirla ni empañarla (In. V). Era lógico que acabada la contienda se impusiera un poder autoritario, pero no debía corresponderse con una Dictadura, o sea, debiera desembocarse en un «Estado liberal democrático» (In. III).

En conclusión, casi todas las ideas expuestas por Alcalá Zamora son un repaso a los defectos de los demás y un repertorio de sus virtudes políticas. Como indica Julio Gil Pecharromán, a propósito de los artículos de La Nación y L'Ėre Nouvelle, con palabras que transcribimos con anterioridad: "En ningún momento hay trazas de objetividad autocrítica [...], sino un análisis de las torpezas y egoísmos de la clase política». Es más, añadimos nosotros, en su opinión, la responsabilidad de lo que sucedió en España 
desde abril a julio de 1936 fue siempre de los otros. A pesar de todo, hay que admitir que la parcialidad en el enfoque de los comportamientos propios y ajenos no impide que le asista la razón en muchas de sus apreciaciones.

\section{LOS CINCO ARTÍ́CULOS RECUPERADOS}

I

L'Intransigeant 15 août 1936, pp. 1 y 5 ,

«Avant la Guerre civile. Président impartial je le fus»

Para explicar lo más claro posible el hecho insólito de mi destitución, voy a prescindir de toda retórica, abreviar el comentario, alejar de mí toda pasión, suprimir todo lo que sea literatura. Quiero que solo los hechos aparezcan con toda sencillez, con sus detalles y con sus datos exactos.

Tras haber combatido continuamente — sin duda más que nadie — la dictadura, los partidos republicano y socialista juzgaron que yo debía presidir el comité revolucionario llamado a convertirse, después del éxito de su acción, en gobierno provisional.

Tal elección se debió a mi personalidad, a mi respeto al orden y a la democracia y, también, al hecho de que era un hombre de leyes que había sido ministro de la guerra y que podría, inspirando confianza al país y a las fuerzas armadas, atraer su adhesión y disminuir sus resistencias.

Tuve la voluntad y la suerte de hacer que triunfara, gracias al apoyo ferviente de la opinión pública, un movimiento revolucionario que, sin perder nada de su grandeza, ha sido el más pacífico de la historia.

Ahora bien, después de haber presidido durante seis meses el Gobierno de la República, dimití porque estaba en desacuerdo con la mayoría de las izquierdas de las Cortes constituyentes respecto a la solución que se dio al problema político-religioso. Consideraba que lo que estaba surgiendo era no solo injusto sino perjudicial para la consolidación del régimen republicano. Con todo, me aparté del Gobierno sin ninguna protesta y, aunque, desde ese momento, el Consejo de Ministros acentuara de forma violenta su parcialidad, no me enfrenté. La verdad es que tampoco tuve tiempo.

Dimití el 14 de octubre. Tras una breve estancia en el campo, al comienzo de noviembre, al poco de llegar a Madrid, recibí la visita de cuatro ministros: un socialista, un radical-socialista, un autonomista y un radical. Venían a solicitarme, rogarme insistentemente, aceptar la presidencia de la República. Los cuatro representaban al Gobierno en pleno y a cuatro quintas partes de las Cortes constituyentes que tenían que elegirme.

Yo no había pedido nada, no deseaba ser elevado al primer puesto de la República. Ya durante la constitución de las Cortes, había rechazado el cargo de la presidencia. 
Durante largo tiempo reflexioné y consulté a mis amigos de la minoría, que no formaban ni una vigésima parte de la Cámara, y comprendimos, después de un tiempo de indecisión que el deber, frente al interés de mi partido, me imponía la presidencia de la República, en primer lugar para consolidar el régimen, ofrecer garantías de imparcialidad a sus partidarios y atraer a la joven República las fuerzas aún no incorporadas. Se votó y, sobre 410 votantes, conseguí 372, a los que yo añadía 15 adhesiones internas. Por tanto, salvo algunas manifestaciones individuales, me había elegido la unanimidad de los partidos.

\section{Un presidente imparcial}

El ejercicio de una alta función se aprecia sobre todo por el uso de las prerrogativas que lleva consigo. Para un presidente de la República, el papel principal consiste en formar gobiernos, nombrar los ministros o aceptar su dimisión. Es lo dispuesto en el artículo 75 de la Constitución española.

Ejercí el cargo de presidente de la República durante 52 meses aproximadamente y he aquí lo que ocurrió con las diferentes fracciones políticas que se sucedieron en el poder: Veamos: Gobiernos de extrema izquierda, republicanos y socialistas, a lo largo de 21 meses. Republicanos, alrededor de 2 meses: desde febrero de 1936 hasta mi marcha (con un amplio horizonte de continuidad abierto a ese Gobierno). Gobiernos de centro y de izquierda, durante 3 meses: de septiembre a diciembre de 1933 . Gobiernos de centro y de derecha a lo largo de 24 meses: de diciembre de 1933 a diciembre de 1935. Gobiernos de centro, solo 2 meses, desde finales de 1935 hasta febrero del año siguiente.

Ninguno de los seis presidentes del Consejo de ministros salió de la minoría que yo dirigí en las Cortes constituyentes, y como ministros designé personalidades que me habían combatido muy vivamente. En el último gabinete, provisto de carteras muy relevantes, hice entrar a dos ministros con los que había roto toda relación como consecuencia de su violencia y de sus ataques. No hice ninguna objeción al nombramiento que se me pedía y que no me imponía ninguna influencia del Parlamento.

El más decisivo y discutido de los poderes del Presidente es, sin duda, la disolución prevista en el artículo 81 [de la Constitución]. Disolví las Cortes constituyentes, las cuales debían cesar automáticamente, tras cumplir su misión, pues su convocatoria no llevaba consigo ninguna duración determinada. Actuando así, legalmente, contrarié a las izquierdas, y las derechas salieron favorecidas.

Tiempo después disolví igualmente las primeras Cortes, tras su duración de dos años. Ahora las contrariadas fueron las derechas y beneficiadas las izquierdas. Después de cada una de estas dos disoluciones, las elecciones establecieron mayorías distintas de las anteriores. Pero lo peculiar en ambos casos fue que los partidos que vencieron en las consultas no estaban representados en el Gobierno que las había convocado. 
El de octubre de 1933, que abrió la vía a la victoria de la derecha, se componía de un presidente y 8 ministros de izquierda y 4 de centro. El de diciembre de 1935, bajo cuya gestión triunfaron las izquierdas, era un Gobierno de centro, y en su primera composición incluía algunos ministros de derecha.

Ninguna de estas elecciones favoreció a al partido fundado por mí, minoría que comprendía 22 diputados en origen y se redujo a tres miembros, después de la primera disolución, y son 6 en la actual Cámara.

El artículo 86 de la Constitución atribuye al Presidente otra prerrogativa muy importante: el veto de suspensión, es decir, el derecho a exigir una segunda deliberación de las Cortes sobre las leyes votadas por ellas. Algo equivalente a lo que existe en los Estados Unidos, de la que hace uso normalmente el presidente de la República.

Esta prerrogativa de veto no la ejercí nunca contra las leyes votadas por las mayorías de izquierda. Para refrenar algunas votaciones exageradas me fue suficiente con llamar la atención del Gobierno, porque este quiso evitarme tener que llevar a la práctica mi poder.

Al contrario, en las Cámaras de mayoría de derecha, utilicé el veto seis veces, con ocasión de leyes que afectaban a la organización militar y tendían a desnaturalizar las reformas llevadas a cabo en el ministerio de la guerra por el Sr. Azaña, jefe de la izquierda, especialmente contra aquellas que restablecían de una forma disimulada los capellanes del ejército; contra otra que favorecía demasiado a los propietarios latifundistas. Hubiera querido vetar también alguna otra ley de la derecha: la que amnistiaba, reintegrándolos en el ejército, a los militares rebeldes o netamente hostiles a la República, pero quien ocupaba entonces el poder no me lo consultó.

Todavía una prerrogativa interesante del jefe del estado que las Cortes votaron atendiendo a mi petición: La que definió el artículo 76, párrafo C de la Constitución. Este artículo prevé que el Presidente puede someter al voto de las Cortes los proyectos de decretos, si considera que son contarios a las leyes en vigor.

Como jurista y hombre de la Administración me he acordado siempre de que disponía de ese poder y he estudiado minuciosamente los decretos. Y, aunque el recurso al arbitraje parlamentario haya sido excepcional, además de facultativo, y resultando de una decisión unilateral del jefe del Estado, conseguí siempre que prevaleciera mi punto de vista ante los gobiernos cuyos decretos quise someter a la votación del Parlamento.

Nunca en estas circunstancias delicadas me preocupé de averiguar si los textos que debía arbitrar procedían de gobiernos de izquierda (bienes comunales, cultivo obligatorio de las tierras, etc.) o del centro y de la derecha (aumento de las tarifas de los ferrocarriles o readmisión de los empleados reaccionarios destituidos o apartados según las leyes de las Cortes constituyentes). Ese no es el asunto.

Cuando paso revista a mis acciones de presidente de la República, compruebo que he desempeñado mi tarea con una regla de imparcialidad absoluta, lo que no significa que haya querido nivelar todos los impulsos. 
Pocas veces he transgredido esta regla de imparcialidad; estoy obligado a constatar que lo he hecho solamente en beneficio de los parlamentos de izquierda, que me han destituido

II

L'Intransigeant, 17 août 1936, p. 3,

«La Guerre civil en Espagne. La vérité sur ma destitution»

Expuse en mi primer artículo la regla de imparcialidad de la que no me separé nunca en el ejercicio de mi mandato de presidente de la República.

Después de haber recordado las circunstancias que me llevaron a abandonar la presidencia de la República, enumeré las más importantes prerrogativas del jefe del Estado español e indiqué cómo en el ejercicio de esas prerrogativas —idurante 52 meses consecutivos! - me impuse la regla rigurosa de no favorecer a mis amigos políticos. Si alguna vez me distancié de esa línea, fue únicamente a favor de mis adversarios de la izquierda... que, finalmente, me destituyeron.

\section{La prerrogativa del veto}

Era un resultado inevitable. Estos adversarios (de los que nadie podía poner en entredicho sus convicciones republicanas) acaso eran un peligro para mí, como pude comprobar a menudo.

Por lo que se refiere a los parlamentarios de derechas, la dudosa simpatía que me testimoniaban en tanto que fundador de la República, venía después del miedo que podían inspirarles, juntas y con razón, su adhesión tardía, sus convicciones... relativas, sus elecciones equívocas.

Desatendiendo los riesgos que pudiera correr mi situación personal de jefe del Estado, me limité a defender las instituciones de la República: y fue por esta razón por la que, en el ejercicio de una de mis prerrogativas — la del veto-, la balanza fue siempre favorable a las izquierdas y contraria a las derechas.

\section{La ausencia de un Senado regulador}

Es probable que el más grave defecto de la Constitución española haya sido la ausencia de un Senado y, en consecuencia, la omnipotencia de una Cámara única, de la que el Gobierno, en régimen parlamentario puro, constituye su emanación. Todos mis esfuerzos para la creación de esta segunda Cámara fueron vanos, y me pude convencer del gran peligro causado por tal estado de cosas: $O$, en efecto, como presidente de la República, me quedaba cruzado de brazos y todos los excesos de la mayoría eran posibles, o bien el Presidente recibía la delicada misión, peligrosa — digamos imposible—, de suplir la ausencia de una Cámara alta y debía vivir entonces en continua lucha con el Parlamento y los gobiernos sucesivos. Sin embargo, después de haber medido los 
peligros de esta misión presidencial y sus consecuencias, me decidí a completar mi tarea y a cumplir con el esfuerzo necesario.

¿Citaría entre mil un ejemplo típico... y capaz de dar una idea de la dificultad de ese papel de árbitro imparcial?

Las Cortes de izquierda habían decidido la expulsión de las universidades de personalidades eminentes —entre ellos estaba uno de los más célebres orientalistas del mundo- bajo el pretexto de que eran ¡sacerdotes católicos! Solo anunciando que yo me opondría a tal vergüenza, presentando veto formal, hice abandonar este proyecto que la Cámara iba a acoger.

Más tarde, la mayoría de derechas quiso, suprimiendo - mediante una ley de efecto retroactivo- la inamovilidad de la magistratura, expulsar del tribunal supremo de justicia - la Cour de Cassation espagnole- a su presidente, jurista eminente a la vez que justo magistrado, por la simple razón de que ¡no había sido bautizado! Es más, previne al Parlamento de que no podía consentir este atentado a la libertad de conciencia y culto y añadí que opondría mi veto a la ley, si se la votaba, y las Cortes abandonaron el proyecto.

En muchos otros casos hube de mantener luchas parecidas contra los excesos de los fanatismos.

Mi papel de medidor al lado de gobiernos sucesivos y de tendencia cada vez más opuesta era especialmente complicado por su carácter urgente y áspero.

Pero tenía la suficiente convicción de que esta mediación era indispensable, pues todos los males que sufría España no habían sido sino consecuencia de guerras civiles, aunque fuera al precio de mi tranquilidad y de mi situación personal. Los acontecimientos iban, por desgracia a probar hasta qué punto lo veía sólo yo.

Las verdaderas razones de mi destitución

La serie de "luchas» continuas a las que me obligó este deber imperioso no es suficiente para explicar mi destitución. Si estos vetos sucesivos descontentaron a todos, ofrecieron, por otro lado, la ventaja de proteger a la colectividad contra una sucesión de actos arbitrarios.

Es necesario, por tanto, buscar en otro lugar la razón de mi salida forzada.

Las etapas fueron rápidas: tan pronto como se constituyó la nueva Cámara, y desde su primera sesión, el pasado 3 de abril, decretó, violando las leyes constitucionales, que yo no debía haberla disuelto. En la sesión siguiente, la del 7 de abril —buscando cualquier pretexto y con el único propósito de destituirme-, los diputados rechazaron aceptar la disolución de las Cortes de derechas — es decir, la Cámara precedente-, que ellos, sin embargo, habían reclamado con el brillo que se conoce...

El Gobierno, que descuidó advertirme, se abstuvo, igualmente, de intervenir en la Cámara y aparentó desinteresarse totalmente del asunto: durante las 104 horas últimas 
de mi mandato, del viernes 3 al martes 7, viví completamente aislado, al haber sido cortadas, incluido el teléfono, todas las comunicaciones entre el jefe del Estado y los miembros del Gobierno.

La historia de las crisis ministeriales nos habían demostrado ya - tales fueron los casos de Millerand o Grévy — una mayoría hostil al jefe del Estado que rechazaba recibir el poder de sus manos... Pero nunca hasta ahora se había asistido a este espectáculo extraordinario: el de un Gobierno que había recibido un mandato del presidente de la República, investido de su confianza, descuidando pedirle la dimisión, "olvidando" incluso advertírselo... y abandonarlo, solo, sin defensa, y exigiendo de la mayoría del Parlamento que lo destituyera.

III

L'Intransigeant, 18 août 1936, pp. 1 y 3,

«Si je suis parti, c'est pour ne pas jeter un fagot au bûcher qui brûle maintenant»

En mis artículos anteriores les he dicho cómo, decidido firmemente a combatir todas las dificultades que mi actitud resueltamente imparcial me iba a ocasionar, concebía yo los deberes del Estado. Señalaba, igualmente, que el más grave defecto de la Constitución española era la falta de un Senado.

De este modo han podido discernir las causas iniciales de mi destitución.

Había indultado a un condenado a muerte

La hostilidad de la nueva Cámara no se encuentra explicada por los discursos alternativos prudentes o reticentes de mis adversarios. Las demostraciones jubilosas que hubo después de la votación no aclararon más el asunto. Alumbradas por el rencor, no hacen que aparezca la menor justificación del hecho. La razón más seria de mi impopularidad fue el acurdo de indulto de un diputado condenado a muerte en 1935. Esta medida de clemencia provocó dos crisis ministeriales en un mes, y, en el Parlamento, exigió una sucesión ininterrumpida de suspensiones de sesiones.

El diputado indultado por mí [el socialista Ramón González Peña] me honró, además, con un odio implacable...

\section{La izquierda republicana}

Sin embargo, es fácil descubrir los verdaderos móviles que incitaron a diferentes fuerzas políticas a fomentar mi salida.

El alma de la empresa fue el partido de la izquierda republicana, con sus coligados sectarios.

Su fórmula: Recuperemos la República y no la perdamos más significa en lenguaje claro: Volvamos al poder y no lo dejemos escapar (las cursivas son suyas). Pero no les era suficiente, con la modificación de las leyes, apoderarse de todas las funciones 
públicas importantes ni con restablecer, crear o inventar para colocar en ellas a sus partidarios de tantos empleos como les permitiera la débil capacidad económica del País y depauperarla aún más. El partido de la izquierda republicana se esforzó aún por todos los medios de los que disponía en derivar en beneficio propio todos los acontecimientos políticos, a fin de satisfacer su amor exclusivo y constante de poder. Para acceder a esta alta función de jefe del Estado, provocó con violencia la vacante necesaria, del mismo modo que para proveerla de un titular se ha tolerado o mantenido la perturbación sistemática del orden público.

\section{Los partidos obreros}

De manera visible los partidos obreros están profundamente divididos, no en dos mitades, sino en dos facciones notoriamente desiguales en número y muy diferentes en sus tendencias. El bloque más importante, que se considera continuador de las doctrinas colectivistas persigue, naturalmente, los fines de la revolución social. Era lógico que contribuyera a derribar el régimen constitucional y democrático de España y todo lo que pudiera representar y defender el orden sobre el que se apoya dicho régimen.

La segunda facción, minoría reducida, republicana de izquierdas, deseaba precipitar un acontecimiento, que, aprovechando las oportunidades y los vacíos de puestos, le permitiera participar y, sin duda, de forma predominante, en el ejercicio del poder.

Las dos minorías regionales de la "conspiración» esperaban alcanzar en recompensa de su acción una ampliación de la autonomía respecto a sus diputados. Los representantes vascos, defensores de la religión, de la unidad católica, de la iglesia de Roma, aportaban una colaboración muy útil, aunque fueran poco numerosos.

Fueron las organizaciones anticatólicas las que ordenaron el reagrupamiento de los partidos interesados en mi salida. La unión heteróclita de esos partidos y el origen del movimiento del que fui víctima quizá explican los actos de indignante ingratitud de los que dieron prueba respecto a mí muchos de mis servidores. Se me ha reprochado ser católico practicante. No obstante, mi papel consistía en garantizar la libertad de conciencia y de culto definido por los artículos 26 y 27 de de la Constitución.

Todos los medios, incluida la amenaza...

Se hicieron tenaces esfuerzos para forzar mi dimisión.

Para condicionarme a renunciar a mis funciones, emplearon todos los recursos, los más viles, los más inadmisibles. La prensa, inspirada por los jefes de la mayoría y con la autorización complaciente de la censura, publicaba regularmente la noticia — falsa - de mi dimisión y daba informaciones —exactas - sobre los preparativos de mi destitución.

Siguiendo el mismo procedimiento, se anunció desde febrero que se fijarían las elecciones municipales para no coincidir con las de compromisarios presidenciales. 
Por otra parte, muchos miembros de mi familia fueron detenidos, sacados de su domicilio. Se les rechazó la protección y la seguridad personales. Se me interceptaron todas mis comunicaciones telefónicas, sin que intentaran negarlo ni ocultarlo. La censura previa, la más dura, la más intolerable que haya conocido España, permitía que circularan las injurias más graves sobre mí, contra las cuales era generalmente inútil recurrir al Código penal, porque la bajeza de los ataques provocó que surgiera, indignada, la protesta de la decencia pública.

Yo, que no había buscado ser presidente de la República, que contaba como días de prisión los de mi mandato, soportaba todas estas humillaciones y provocaciones, porque la inmensa mayoría de España, todos los partidos de la oposición (incluidos en ellos mis mayores enemigos) y la opinión neutral veían en mi mantenimiento la suprema, la única garantía de los derechos constitucionales.

La tarde del 7 de abril, a las cinco, el conjunto de los grupos que habían decidido mi destitución me mandó un emisario de parte del Presidente de las Cortes, de acuerdo con el presidente del Gobierno, para notificarme lo que se había decidido y aconsejarme que, para evitar la violencia que pudiera venir de la muchedumbre exaltada, dimitiera. El deseo de arrancarme la dimisión era tal que no les detenía ni la amenaza con las brutalidades de la multitud contra la residencia de la familia y la persona de quien era aún el jefe del Estado.

La votación del 3 de abril

Los recursos que emplearon para obligarme a una renuncia pueden parecer verdaderamente extraordinarios.

Un acto de estas características viola manifiestamente el artículo 81 de la Constitución, pues cuestiona la disolución de las Cortes cuya iniciativa fue mía y gracias a la cual la mayoría de ahora tiene el poder. Hay una usurpación notoria en la votación del 3 de abril, cuando la Cámara estimó, ella sola, que existía un desacuerdo con el jefe del Estado en cuanto a esta cuestión litigiosa: la disolución de las Constituyentes. Porque no solamente no se observó la regla constitucional de un anuncio previo de tres días, sino que se votó por sorpresa, en la abusiva prórroga de una sesión ya prolongada. Además, la votación era nula: no había quórum - la mayoría, que debía ser de 200, fue solo de 181—, de modo que la mayoría del 7 de abril se pronunció contra el principio lógico, ético y jurídico de sus propios actos.

\section{Marchándome, cumplí con mi deber...}

En efecto, los acuerdos fueron un golpe de Estado parlamentario sin precedentes ni posible justificación.

Además, había otros motivos que, para algunos, hacían deseable mi partida, porque mi dimisión tendría el aspecto de una deserción. Igualmente, muchos diputados que, numéricamente, completaron la mayoría, evitaban así dar el espectáculo de 
su participación en la destitución del jefe del Estado, en el momento en que, como subsecretarios, directores generales o embajadores acababan de abandonar mi propio gabinete o salir de una audiencia de cortesía o de agradecimientos por los nombramientos con que los había gratificado.

Conociendo mi derecho, seguro de que una resistencia al golpe de Estado premeditado por las Cortes era legítima, estaba asimismo seguro de que no me faltaban medios ni apoyos eficaces. Con el temor de que no me sometería de inmediato, los jefes de la mayoría habían querido servirse de la sorpresa. El presidente de las Cortes y el Gobierno mismo me dieron la seguridad de que la última disolución había sido regular y me invitaron a permanecer en mi puesto y que declarara que estas nuevas Cortes no podían ser ya disueltas por mí. El lunes 6 de abril, el presidente de la Cámara, que un día después iba a reemplazarme como [jefe del Estado] interino, me visitó en palacio, para anunciarme que el miércoles 8 me pediría fijar la hora en la cual él podría presentarse como presidente de la República acompañado de la mesa del Parlamento

Pues bien, el día 8, al comenzar el día, vino al palacio, no para saludarme, sino para destituirme (la cursiva es suya). La mesa, que me había anunciado una visita cortés, a la hora que me conviniera, entró en mi casa casi de noche, intentando obligarme a comparecer en persona, a lo que me resistí.

Sé y sabía por adelantado el reproche que me sería dirigido por la Historia y que entiendo ya: no haber defendido mi derecho. Pero no lamento lo que hice, porque sabía desde el último diciembre —y la prueba escrita se encuentra en las actas de mi vida oficial y privada - que en abril de 1936 no sería ya presidente de la República española, que el decreto de disolución conducía a mi caída. Pero sabiéndolo, publiqué el decreto sin vacilar porque la necesidad política, mi conciencia y la voluntad del país lo exigían.

¿Defender mi derecho?... Prevenido y consciente, como estaba, de las consecuencias atroces de las guerras civiles españolas en el curso de la Historia, no podía arrojar más leña al fuego que ardía entonces. ¿Para defender mi puesto?... No, no más asesinatos ni incendios. Se habría podido creer que me guiaba la ambición, jmientras cumplía solamente con mi deber! En medio de las complejidades de este deber, cré́, creo y creeré siempre que lo fundamental era no contribuir a lo que avivó, agravó, extendió la lucha desencadenada por la pasión de los demás.

\section{IV}

L'Intransigeant, 27 août 1936, pp. 1-3,

"La voix de la concorde peut-elle être entendue?»

Para que renazca la paz en España haría falta el despertar del espíritu nacional

Desde mi llegada a Francia, un nuevo interrogante, ardientemente humano, reflexivo y generoso reemplaza a la curiosidad frívola que me asaltaba en las diversas etapas del camino. En presencia de la magnitud de la desgracia de España, no me pregunto ya 
quién será el imposible vencedor. Con una piadosa y emocionada inquietud frente a los horrores sufridos y sus enormes peligros, busco con ansiedad la voz de la mediación o, simplemente, la llamada a la concordia. Respondiendo a esta noble inquietud, quiero hacer un examen objetivo, imparcial y rápido de todas las posibilidades de mediación. Tengo, ipor desgracia!, la tristeza de encontrar pocas y de constatar que solo representan una relativa oportunidad, una influencia problemática. He aquí la convicción dolorosa, aunque sincera, de un hombre de buena fe que no ha renunciado nunca a la lucha por un ideal, pero que encuentra los horizontes del optimismo muy ensombrecidos, por no decir cerrados. ¿Queda, al menos, la esperanza de un eco lejano y milagroso? Ahogado por el fracaso espantoso de la guerra civil, la voz de la concordia es desesperada, dramática, estéril. Encuentra los oídos sordos y las almas hostiles.

\section{No hay neutralidad posible}

Y, sin embargo, ¿đónde la meditación y la concordia significan ventajas más considerables que para el combatiente de la guerra civil? Y no lo es sólo porque la victoria conseguida a costa de su propio país no es seguro que sea respetada y reclame una vigilancia implacable, la cual exija casi el aplastamiento, la extinción del adversario. Lo es también porque el hecho de perder en una guerra civil lleva consigo la más severa condena moral. Ni aquel que ha arriesgado la puesta en práctica desesperada de medios prohibidos ni el que se defiende contra él en esta lucha que recuerda el antiguo juicio de Dios, pueden emitir una propuesta de paz, por miedo a que sus adversarios consideren la oferta como señal de debilidad o a que el fanatismo de sus propios partidarios la vean como una deserción.

Incluso en el interior de España, como en cualquier otro país, es difícil que haya neutrales y, si los hay, el silencio es obligatorio. La neutralidad cada día es más difícil en el caso de guerra exterior, resulta imposible si se trata de una guerra civil, sean cuales sean los deseos y el estado de ánimo de la gente. Si su voluntad no los suma espontáneamente en una opinión, la fuerza del prójimo los arrastra. Si son débiles y pusilánimes se someten a la primera tropa que se acerca o los amenaza. Si son fuertes y orgullosos se vuelven contra el primero que los persiga o provoque.

Aunque se revelara alguna alta figura que encarnara providencialmente con autoridad la idea de la concordia, sin embargo, la expresión de su generoso propósito sería considerada casi un crimen de guerra perpetrado para minar la moral de los combatientes. Y, si por convicción, arriesgando el todo por el todo, llegara al heroísmo de hablar, el sacrificio sería probablemente inútil ante un rechazo que no le prestaría ni si quiera la menor audiencia.

Si una voz española se elevara hoy para proponer la paz, se le reprocharía haberse callado hasta aquí y se le negaría cualquier autoridad por ser tardío e improvisador. Si hubiera hablado a tiempo, advirtiendo, mostrando el peligro de muerte, quizá sería 
juzgado hoy mismo odioso, porque la confirmación trágica y aplastante que han venido a darle los hechos, en lugar de reforzar su autoridad, irritaría el amor propio de los beligerantes, imprevisores antes, ciegos ahora.

\section{Los fanatismos opuestos}

Si se me pregunta quién es el español que tiene la menor autoridad sobre los que combaten, quién es el que ha sufrido más el fuego cruzado de sus ataques y de sus injusticias, diré —y naturalmente se podría individualizar- que es el que más se esforzó en impedir la guerra civil, quien entrevió mejor su inminencia y su catástrofe, quien mas resistió los fanatismos opuestos y extremos. Cada uno de estos puede comprender al otro y, de esta manera, aceptarlo, porque le es del todo necesario. A fin de cuentas, el fanatismo no se corresponde con la ideología sino con el temperamento. Permite incluso pasar de un extremo a otro. No se comporta en el campo de la lógica sino que obedece a la psicología del impulso, ni siquiera a la del instinto. Los que siguen una influencia semejante, lejos de reconocer la preeminencia, incluso solo relativa o momentánea de un arbitraje imparcial, lo mirarían con desconfianza y desprecio.

Si el horizonte parece así de sombrío, cuando se piensa en cualquier iniciativa española, el deseo de encontrar una solución y la necesidad de llevar a cabo un examen completo atraen la atención de fuera de las fronteras de la patria. Sin embargo, hace falta, desde ese momento, continuar con la serie de dolorosas exclusiones. La gran fuerza moral que, si frecuentemente en la Edad Media e incluso después ejerció en España una influencia espiritual y conciliadora, hoy se encuentra en la imposibilidad de hacerse entender, aislada, como está. Para convencerse, para prever el fracaso que podrá seguir el más grande poder encerrado en la ciudad más pequeña, en la ciudad que delimitaron los acuerdos de Letrán, sería suficiente, sin invocar recelos políticos, recordar las horribles fotografías de esta salvaje destrucción que, ya algunas semanas antes de la guerra civil, asoló la grandeza artística, al mismo tiempo arquitectónica e inmaterial de España.

\section{¿La intervención de una nación extranjera? ¡Difícil!}

El concepto de intervención exigiría, igualmente, en una Europa menos dividida y menos desafiante, el acuerdo de grandes potencias. Por desgracia, la consciencia de una solidaridad europea desgarrada del exterior desde 1914 y estremecida desde mucho tiempo antes, se disgregó del mismo modo ante la realidad de ideales políticos contrarios, de concepciones en lucha, que han destruido la esencial coincidencia de regímenes tal como se dibujaban antes con sus matices y su variedad. Toda acción unilateral sería extremadamente peligrosa y la tentativa de una acción concertada sería arriesgada, sin que ofreciera el máximo de probabilidades de éxito, salvo que fuera más allá de la conformidad expresa o tácita. Pero esta que puede tranquilizarnos, alejando la 
perspectiva de una catástrofe en la que la civilización del viejo mundo sería arruinada definitivamente, deja en pie todavía subsistiendo y ardiendo, aunque no se eche más combustible a la hoguera..., el incendio que consume a España, incendio capaz de propagarse cualquier día y, por otra parte, vuelve mudo e ineficaz el sentimiento de horror y de fraternidad de las conciencias honestas.

\section{¿La S. D. N.?... ¡Ilusorio!}

Una acción mediadora de la Sociedad de Naciones no se alejaría de los límites de su competencia y no haría temer ese superestado del que siempre se ha temido su aparición, porque la institución de Ginebra, sin mezclarse en el futuro régimen interior de la vida española, podría creer y alegar que se encuentra en presencia de una situación donde la paz entre los miembros está gravemente comprometida. En ausencia de objeción doctrinal, surgiría un escollo debido al hecho de que un acuerdo del Consejo, después de su reunión hasta la realización de dicho acuerdo, supone una coincidencia de puntos de vista entre las grandes potencias y, al no poder conseguir esta coincidencia por las vías diplomáticas directas, la solemne y colectiva deliberación podría añadir la ineficacia de la intervención.

\section{¿Portugal?... Su régimen político lo rechaza}

Hay en la Península Ibérica otro pueblo hermano de España, que desea ciertamente la paz en ella, como todo español sensato desea la grandeza y buena suerte de Portugal. Al margen de las rivalidades europeas, no despierta confianza ni por ella misma ni por su alianza secular con Inglaterra, país que, sin dar prueba de su simpatía por la reacción y la demagogia, debe combinar su respeto de la libertad con el del orden. Pero, si por causas perfectamente explicables, se ha podido producir en la historia política de Portugal y de España, en la época de los ministros reformadores, en la lucha contra el absolutismo, con la llegada de la República un impresionante paralelismo coincidente hasta en los detalles, a veces, no ha podido existir siempre una simultaneidad absoluta, cronometrada. Los dos relojes de la historia peninsular se encuentran ahora en una de sus desviaciones del péndulo y la diferencia entre uno y otro régimen, combinada con el estrecho contacto territorial, está muy acentuada para que se despierte alrededor de ella la desconfianza de los beligerantes.

$$
\text { ¿Los neutrales, entonces?... Quizá... }
$$

Es posible que el grupo de neutrales de la Sociedad de Naciones tenga, sin embargo, una acción fácil, aunque sea de una influencia débil e indirecta. Los pueblos cultos y pacíficos, ordenados y libres, han tenido casi siempre a su lado y frecuentemente como portavoz a España, cuya suerte debe causarles una preocupación desinteresada. A la debilidad de su influencia se une, acaso, la dificultad del ambiente político que reina 
en sus países. La solidaridad convencional y mística de etiquetas, de expresiones y de banderas mide, en ocasiones, un abismo entre lo que entienden, sostienen y condenan de un país a otro.

He hablado de todas las maneras y con todas las influencias posibles en la Organización de Estados europeos. ¿Hace falta algo más fuera de ese marco político o de este viejo territorio? Quedan los partidos, quedan las elites intelectuales, artísticas, morales que, sin que teman exclusivismo o lo compensen por el conjunto de sus tendencias, conservan toda la autoridad necesaria para condenar los horrores que destruyen un gran pueblo y ultrajan toda la civilización.

\section{El espíritu nacional español}

Queda, en fin, empañada pero no oscurecida, lejana pero no quimérica, la esperanza de esta maravillosa clarividencia que, en las horas críticas ha salvado a España cuando rodaba ya hacia el abismo. Si no ha perdido la fuerza que ha sido su salvación, comprenderá que el pueblo que ha escrito la página sin igual, prodigiosa del 14 de abril, trascendental y pacífica, no tiene el derecho de destruirla ni de empañarla.

Y el que, con todo el impulso de su espíritu afligido, desee la concordia definitiva y no la tregua pérfida — que no hace sino reparar las fuerzas y aumentar los odios, para destruir en seguida mejor los valores espirituales, las riquezas materiales y las vidas humanas- debe convencerse de que no hay otra solución.

$\mathrm{V}$

L'Intransigeant, 1 décembre 1936, p. 1, «Si l'on veut éviter l'écroulement final de l'Espagne...

Une seule solution : il faut une entente des nations"

Cada día que pasa en la descomposición de mi país encierra hora tras hora un riego de grave alarma para todo el mundo. No sólo se trata aquí de peligros ocasionales que puede engendrar la fatalidad hacia fuera de España y sus aguas territoriales. Tampoco se trata de propósitos fantásticos o secretos que se atribuyen a ciertas potencias extranjeras, sino de peligros que encierra en ella misma la guerra civil española acantonada en su territorio peninsular y que se extendería con facilidad fuera de sus límites. El deber de un patriota es hacer estas observaciones, por delicadas que resulten.

España debe decidir con absoluta soberanía, libre y pacíficamente la manera como desea organizar su vida y si quiere darse un régimen centralista, autonomista o federal. El hecho de que deba, para ello, recurrir a las armas, doloroso en sí mismo, se agrava - al tiempo que se dobla en humillación- por el hecho de que conduce a algunos a admitir, incluso a preconizar, la amenaza o la ayuda del extranjero. Sistema que dota de siniestras facilidades a quienes desean menoscabar el principio de integridad territorial, el límite sutil de la soberanía y de la independencia, y correr el riesgo y las inquietudes de una ruptura del equilibrio. 
La historia ha consagrado la existencia de la Península Ibérica con dos Estados provistos de plena soberanía y nadie ha podido borrar la solidaridad indestructible creada por la naturaleza, gracias a la cual puede haber en esos dos Estados un mismo régimen político que facilita las relaciones de confianza y cordialidad. Igualmente, uno puede encontrarse ante dos regímenes distintos pero sin hostilidades entre ellos. Entonces, la diversidad que subraya la independencia sagrada es edificante en proporción al respeto mutuo que se muestran los gobiernos por encima de la incomprensión sectaria. Con toda mi alma me esforcé en alcanzar esta armonía como base de mi actividad política, durante la cual profesé tanto respeto y afecto hacia Portugal como los que hubiera podido tener hacia mi propio país, si yo no hubiera sido hijo de esta España hacia la que tengo un amor más fuerte aún, puesto que se halla presa de las desgracias que tanto quise evitar a mi patria.

Pero si todo esto es posible, parece, por el contrario, difícil ver coexistir al mismo tiempo dos soluciones evidentemente contradictorias, agravadas por un proselitismo ácido de expansión. Si tenemos en cuenta el empeoramiento aportado a esta situación por quienes irán a buscar un asilo al extranjero para huir de la muerte, porque los arrojan de sus casas, habrá que reconocer una máxima tensión que comporta constante amenaza. A quien no vea esto y no se dé cuenta de las inquietudes provocadas por tales contingencias, le falta la agudeza de la vista de un hombre de Estado e incluso de un observador corriente.

\section{Solidaridad de España con la democracia occidental}

Ninguno de los que viven en contacto con la realidad puede dudar de que una vez que acabe la guerra, a ella le seguirá una concentración de un poder autoritario, con extensas facultades y de larga duración, con el doble fin de deshacerse de la catástrofe e impedir que se repita. Sin embargo, hay una enorme diferencia entre esta necesidad manifiesta, pero transitoria, aunque prolongada, y el establecimiento sistemático, deliberado, definitivo de cualquier género de dictadura de este tipo que se llama totalitaria y que constituye la negación del estado liberal y democrático. Si semejante posibilidad toma cuerpo en España y esta debe incorporarse a cualquiera de los sistemas dictatoriales, el peligro para las democracias occidentales es enorme, por la extensión y la intensidad que adoptaría el hecho. La zona correspondiente aún al régimen democrático esta ya reducida de tan alarmante manera que resistiría difícilmente al ejemplo de un nuevo avance del concepto de dictadura, sea cual sea, su orientación. Por lo demás, se impone la dolorosa confesión en este momento de trágica y suprema sinceridad de que una dictadura extremista en España tendría un carácter de fanatismo ultra-rojo o ultra-reaccionario inconcebible, incluso para aquellos que creerían tener alguna afinidad con las gentes de la extrema-izquierda o de la extremaderecha. Y la nueva hoguera sería provista de tal virulencia que pondría en peligro 
hasta la existencia de todas las democracias todavía estables: crisis de la civilización que podría adquirir rápidamente la apariencia simultánea de una revolución interior en forma de prólogo y de una guerra exterior a manera de epílogo.

\section{Sentido de las posibles soluciones}

Si se quiere evitar realmente el derrumbamiento final de España y la extensión al mundo entero de las consecuencias de una espantosa tragedia, no hay otra solución que la que sigue: hace falta un acuerdo entre las naciones que, si no llega a una mediación, constituya al menos un elemento de aislamiento, mientras ella busque poner fin a una guerra cuya actual duración es ya inadmisible y cuya prolongación constituiría un verdadero exterminio. Por otro lado, las organizaciones de socorro deben de aquí en adelante preparase con vistas a la reconstrucción de España, pieza irremplazable en el edificio internacional y que no puede ser entregada como un campo de experiencia a fórmulas y máquinas destructivas. Es conveniente asegurar el respeto absoluto y la integridad total de este país, su plena y libre soberanía para decidir sobre las autonomías regionales como sobre cualquier otro asunto. Hace falta que se forme allí un poder a la vez fuerte y justo — cualidades que se complementan, lejos de contradecirse- que garantice sinceramente, después de un periodo de régimen autoritario, la posibilidad del establecimiento de un régimen constitucional de carácter democrático y republicano. No debe subsistir ningún peligro de fricción entre los dos estados peninsulares. Es necesario que desaparezca la ilusión e, igualmente, la posibilidad de ver a España, por débil e indigente que se encuentre, transformada en un campo de expansión o de ensayo, en cualquier cosa que tienda a ponerla en servidumbre, en tutela, a gravarla de hipotecas y de fianzas.

Casi no se puede negar la dificultad de alcanzar una solución feliz, pero tampoco se puede discutir la necesidad de ella. Quien no haga nada para facilitarla — sin percatarse de los que la impidan o la hagan desviarse del buen camino- adquiere, incluso se reviste del título de beligerante, la más terrible responsabilidad ante su país y ante la Historia. 